\title{
CA 19-9 ELISA test: a new method for studying mucus changes in tears
}

\author{
C Garcher, A Bron, C Baudouin, L Bildstein, J Bara
}

\begin{abstract}
Aims-This study investigated mucus changes in the tears in various eye conditions using impression cytology. The quantity of mucins was measured by enzyme linked immunosorbent assay (ELISA) using the tumour marker CA 19-9. This assay quantifies the sialylated Lewis ${ }^{a}$ structure mainly associated with ocular mucins.

Methods-Impression cytology was performed using a cellulose nitrate membrane, on 53 healthy patients, 50 glaucoma patients treated with $\beta$ blockers, 24 patients suffering from dry eye syndrome, and 45 contact lens wearers. The tear film glycoproteins were eluted and CA 19-9 was measured.

Results-CA 19-9 content expressed as kilo units (kU) per $\mu \mathrm{g}$ of tears was significantly decreased in dry eye syndrome $(25.8 \mathrm{kU}($ SD 17.3)/ $\mathrm{\mu g})(\mathrm{p}<0.05)$, glaucoma patients over 60 years $(28.9(19.5) \mathrm{kU} / \mu \mathrm{g})$ $(p<0.05)$, and contact lens wearers $(28.4$ $\mathrm{kU}(18) / \mu \mathrm{g})(\mathrm{p}<0.05)$, when compared with healthy individuals $(39.4 \mathrm{kU}(22.2) / \mu \mathrm{g})$.

Conclusion-Impression cytology can be regarded as a valuable method for obtaining samples of glycoconjugates of mucin. The decrease of sialylated chains observed with this method confirms the hypothesis that some quantitative changes in the tear film may be encountered in ocular surface disorders.
\end{abstract}

(Br f Ophthalmol 1998;82:88-90)

Department of Ophthalmology, CHU Dijon, France

C Garcher

A Bron

L Bildstein

Department of Ophthalmology, CHU Ambroise Paré, Paris, France

C Baudouin

INSERM U 55, Hôpital Saint-Antoine, Paris, France

J Bara

Correspondence to: Catherine Garcher,

Department of

Ophthalmology, Hôpital

Général, 3 rue du Faubourg

Raines, 21000 Dijon, France.

Accepted for publication 13 August 1997
Impression cytology is a quick and minimally traumatic technique for collecting superficial conjunctival cells. This method has been used particularly in dry eye where it has shown characteristic cytological changes. ${ }^{12}$ The difficulty of collecting tears without stimulation, especially in dry eye syndrome is well known. ${ }^{3}$ Van Haeringen noted that cellulose sponges or filters tend to pick up mucins and epithelial cells from the ocular surface. ${ }^{4}$ Impression cytology collects not only superficial conjunctival cells, but also the tear film absorbed into the membrane. The nitrocellulose filters harvest superficial conjunctival cells (including goblet cells) and the conjunctival mucus network adjacent to conjunctival goblet cells. We have recently shown that sialylated Lewis ${ }^{a}$ carbohydrate epitope was strongly expressed in the normal conjunctival epithelium. The monoclonal antibody (MAb) NS 19-9 directed against NeuAc-Lea stained both ocular epithelial and goblet cells. ${ }^{5}$ Therefore, MAb NS 19-9 was used in this study to identify the glycocon- jugate content of the tear film and superficial conjunctival cells. An enzyme linked immunoabsorbent assay (ELISA) was developed for the detection of the tumour marker CA19-9 in the blood of patients suffering from neoplastic diseases. We investigated the value of this method in estimating the glycoconjugate content of the tear film.

\section{Materials and methods}

PATIENTS

After obtaining fully informed consent from patients, impression cytology was performed in different groups as follows:

Group 1: healthy individuals who were not suffering from any ocular disease. Smokers, volunteers with systemic disease known to interfere with conjunctiva, or suffering from tumours were excluded. Any topical treatment during the past 6 months was considered as an exclusion criterion.

Group 2: patients suffering from primary open angle glaucoma and treated with topical $\beta$ blockers for at least 1 year.

Group 3: patients with clinical and laboratory evidence of dry eye syndrome. Diagnosis of dry eye was made on the basis of subjective symptoms, Schirmer test (less than $5 \mathrm{~mm}$ for 5 minutes), tear film break up time (less than 10 seconds), rose bengal score (more than 4 using the scoring system proposed by Van Bijsterveld) and impression cytology with significant signs of squamous metaplasia according to the scoring scheme of Tseng. ${ }^{6}$

Group 4: asymptomatic contact lens (CL) wearers without clinical conjunctival change.

We collected impression cytology samples from 53 healthy patients (group 1) whose ages ranged from 20 to 95 (35 females and 18 males). The second group comprised 50 glaucoma patients whose ages ranged from 20 to 94 years (17 females, 33 males). Group 3 consisted of 24 patients, whose ages ranged from 25 to 80 years (17 females, seven males). Group 4 consisted of 45 patients wearing contact lenses, whose ages ranged from 20 to 65 years ( 35 females, and 10 males): 38 patients wore soft CL and seven hard CL.

COLLECTION OF TEARS AND CA 19-9 ASSAYS Impression cytology discs (Cellulose nitrate membrane, Biopore, $30 \mathrm{~mm}$ Millicell-CM) were trephined with an $8 \mathrm{~mm}$ diameter trephine (Trephine super blade 8.0, Pharmacia). These precalibrated $8 \mathrm{~mm}$ diameter discs were applied on the superior bulbar conjunctiva after topical anaesthesia. After 5 seconds, the membrane was gently removed and immersed in a micro tube (micro tube Treff, 0.5 


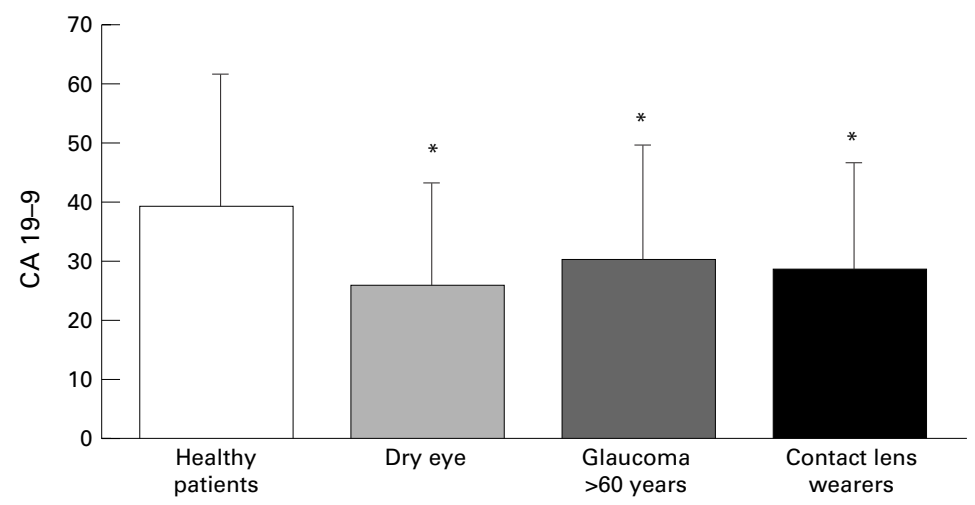

Figure 1 CA 19-9 contents in tear film in different ocular pathologies. Results are given in $10^{3}$ units of $C A 19-9$ per $\mu g$ of tears.

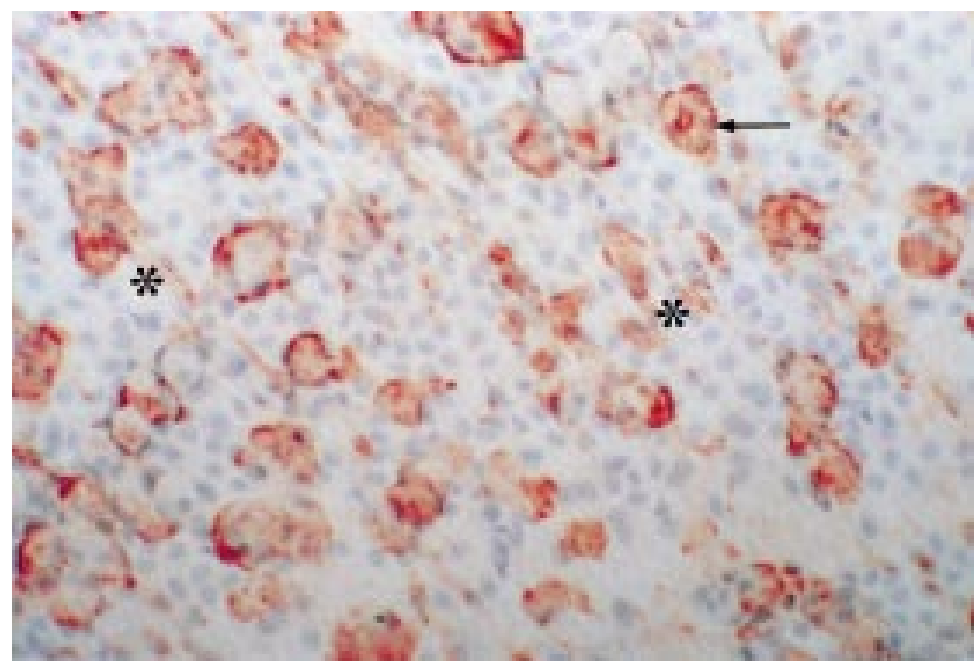

Figure 2 Impression cytology stained with Mab NS 19-9 (patient Lewis ${ }^{a}$ ). Goblet cells (arrow) are stained with Mab. Cell nuclei are stained with 1\% haematin. Positive strands of mucus $(*)$ collected during sampling are also layered at the surface of the filter $(\times 300)$.

$\mathrm{ml})$, filled in with $200 \mu \mathrm{l}$ of the buffer used for CA 19-9 assays (Abbott). The weight of tears and cells collected on each membrane was measured (Precisa 40 SM 200 A). The tube was incubated for 24 hours at $4^{\circ} \mathrm{C}$. After removing the filter paper, we measured the concentration of CA 19-9 in the buffer including the eluted tears by immunoenzymofluorometry. The results were expressed in $\mathrm{kU}$ of CA $19-9 / \mu \mathrm{g}$ of tears.

\section{Results}

WEIGHT OF TEARS

The weight of tears collected in healthy patients $(6.6(1.9) \mu \mathrm{g})$ was not statistically different from the weight collected in dry eye patients $(6.4(1.8) \mu \mathrm{g})$, or in CL wearers (6.6 $(2.7) \mu \mathrm{g})$. In contrast, the weight of tears collected from glaucoma patients treated with $\beta$ blockers was statistically higher $(7.6(2.5) \mu \mathrm{g})$ than in healthy patients $(\mathrm{p}<0.05)$.

CA 19-9 IMMUNOFIXATION

No statistically significant difference in the quantity of marker present was noted according to age or sex-that is, $225(136 \mathrm{kU}$ per filter before 26 years, 249 (117) kU per filter between 26 and 36 years, 191 (113) kU per filter between 37 and 59 years, and 331 (127) kU per filter between 60 and 89 years.
In healthy patients, the content of CA 19-9 was $39.4(22.2 \mathrm{kU}) / \mu \mathrm{g}$ of tears. This was statistically different $(\mathrm{p}<0.05)$ from the concentration of tears of dry eye patients (25.8 (17.3) $\mathrm{kU} / \mu \mathrm{g})$ or of CL wearers $(28.4(18.0) \mathrm{kU} / \mu \mathrm{g})$. In glaucoma patients, the concentration of CA 19-9 was found to be statistically different only above 60 years: 28.9 (19.5) $\mathrm{kU} / \mu \mathrm{g}$ versus 51.9 $(24.4) \mathrm{kU} / \mu \mathrm{g}$ in healthy patients over 60 years $(\mathrm{p}<0.05)$. No statistically significant difference was found between the soft and the hard CL wearers. All these results are displayed in Figure 1.

\section{Discussion}

Impression cytology is a relatively atraumatic and repeatable method of collecting superficial conjunctival cells. It is the most widespread technique for the detection and grading of squamous metaplasia. ${ }^{6}$ Many techniques have been used to collect tears. Mechanical stimulation (Schirmer paper) increases contamination due to serum leakage. Collection of tears with a capillary tube is sometimes difficult especially in dry eye patients. Impression cytology is known as a good technique to collect superficial cells and adjacent mucus layer (Fig 2).

Lectins binding saccharide residues have also been used routinely to characterise glycoconjugates. ${ }^{78}$ Some studies have shown a decrease in the sialic acid content of tears in the dry eye syndrome and in contact lens wearers. $^{9}{ }^{10}$ This probably partly explains the change in physical and functional properties of mucus in these situations. ${ }^{112}$ Monoclonal antibodies are frequently used for studying conjunctival cells. More recently, impression cytology has provided us with good specimens for immunochemistry. ${ }^{13}$ Goblet cells can be stained with specific anti-M1 monoclonal antibodies directed against the peptidic core of mucins. ${ }^{14}{ }^{15}$ These cells are also stained with monoclonal antibodies directed against saccharide moieties of mucins. Such antibodies characterised Lewis related carbohydrate antigens. We have previously shown that goblet cells and epithelial cells could be detected by the MAb NS 19-9 revealing the NeuAc-Lea epitope. ${ }^{5}$ Levels of NS 19-9 can be detected with a semiautomated method used in many hospitals. Levels of MAb NS 19-9 are very low in blood collected from healthy patients (below $17 \mathrm{U} / \mathrm{ml}$ ). This made us reasonably sure that glycoconjugates detected with this method are collected from the tears and conjunctival cells, and not from the plasma during sampling.

The fact that $\beta$ blocker formulations induce changes in the conjunctival surface is well known. ${ }^{16-18}$ The mucus layer is likely to be particularly sensitive to chronic treatment and it is probable that preservatives are responsible. Steuhl observed a reduction in the number of microplicae and a rupture of the intercellular junctions in the epithelial cells of patients and animals undergoing topical treatment with a commercial preparation of timolol maleate. ${ }^{19}$ Conjunctival biopsies revealed stratification of the conjunctival epithelium with separation of the superficial layers. Impression cytology has already been used to demonstrate the decrease 
in goblet cells following chronic topical treatments. ${ }^{16}$ Decrease in CA 19-9 levels confirmed the loss of goblet cells and the fact that the treatment impaired the quantity and the quality of the mucus layer of the tear film. ${ }^{17}$

The same abnormality has been observed in contact lens wearers. ${ }^{20}$ Versura et al demonstrated that goblet cells produce different types of glycosidic residues. Wearing contact lenses induced a significant decrease in the distribution of sialic acid in the goblet cells. ${ }^{8}$ The fact that the CA 19-9 content of the tear film is decreased in contact lens wearers confirmed the view that contact lens wear contributes to the failure of tear film stability. During contact lens wear, the content of sialic acid decreases in tears. The shift in acid glycoconjugate increases tear viscosity. Neu-Ac should be able to influence the viscous property of mucins.

So our study confirms that ocular mucins are sialylated. However, our technique suffers from certain inadequacies. Firstly, we are not able to measure CA 19-9 in Lewis negative patients because CA 19-9 is only detected in patients expressing the Lewis gene (expressed by $90 \%$ of the French population). Moreover, we used elution of mucin from impression cytology under the assumption that elution was constant. Although we used the same buffer and the same time for elution, we cannot be sure that elution of mucins was complete.

This technique used MAb directed against carbohydrate moieties. Whereas anti-M1 antibodies are specific for mucus, MAb directed against Lewis related carbohydrate antigens are not, since they characterise carbohydrate chains of the mucins. Nevertheless, it allowed us to measure quantitative changes occurring in various conditions of the ocular surface, which may reflect changes in mucin qualitative properties. This aspect is of particular relevance when we want to appreciate not only the quantitative aspect of tear production but also the qualitative features that induce mucus diseases.

\section{Conclusion}

Although measurement of ocular mucins in the tear film remains difficult, we have proposed a technique using impression cytology and measurements of glycoconjugates with mono- clonal antibodies. This study confirms the fact that sialylated chains decrease in the dry eye syndrome, in contact lens wearers and in glaucoma patients treated with $\beta$ blockers. Impression cytology may be a useful tool for mucus collection and should be used to study mucin dysfunctions.

1 Kinoshita S, Kiorpes TC, Friend J, Thoft RA. Goblet cell density in ocular surface disease. A better indicator than tear mucin. Arch Ophthalmol 1983;101:1284-7.

2 Friend J, Kiorpes T, Thoft RA. Conjunctival goblet cell frequency after alkali injury is not accurately reflected by quency after alkali injury is not accurately reflected by aqueous tear mic

3 Stuchell RN, Feldman JJ, Farris RL, Mandel ID.The effect of collection technique on tear composition. Invest Ophthalmol Vis Sci 1984;25:374-7.

4 Van Haeringen NJ. Clinical biochemistry of tears. Surv Ophthalmol 1981;26:84-96.

5 Garcher C, Bara J, Bron A, Oriol R. Expression of mucin peptide and blood group $\mathrm{ABH}$ - and lewis-related carbohydrate antigens in normal human conjunctiva. Invest Ophthalmol Vis Sci 1994;35:1184-91.

6 Tseng SCG. Staging of conjunctival squamous metaplasia by impression cytology. Ophthalmology 1985;92:728-33.

7 Versura P, Maltarello MC, Cellini M, Caramazza R, Laschi R. Detection of mucus glycoconjugates in human conjunctiva by using the lectin-colloidal gold technique in TEM. II A quantitative study in dry-eye patients. Acta Ophthalmol (Copenh) 1986;64:451-5.

8 Versura P, Maltarello MC, Cellini M, Marinelli F, Caramazza R, Laschi R. Detection of mucus glycoconjugates in human conjunctiva by using the lectin-colloidal gold technique in TEM. III A quantitative study in asymptomatic contact lens wearers. Acta Ophthalmol (Copenh) 1987;65:661-7.

9 Cabezas JA, Porto JV, Frois MD, Marino C, Arzua J. Acide sialique dans les larmes humaines. Biochim Biophys Acta 1964;83:318-25.

10 Wright P, Mackie IA. Mucus in the healthy and diseased eye. Trans Ophthamol Soc UK 1977;97:1-7.

11 Moore JC, Tiffany JM. Human ocular mucus. Chemical studies. Exp Eye Res 1981;33:203-12.

12 Adams AD. The morphology of human conjunctival mucus. Arch Ophthalmol 1979;97:730-4.

13 Baudouin C, Garcher C, Haouat N, Bron A, Gastaud P. Expression of inflammatory membrane markers by conjunctival cells in chronically treated patients with glaujunctival cells in chronically treated p

14 Bara J, Gautier R, Le Pendu J, Oriol R. Immunochemical characterization of mucins. Polypeptide (M1) and polysaccharacterization of mucins. Polypeptide (M1) and polysac-

15 Kordari P, Zamora PO, Kjeldsen T, Gautier R, Bara J. Comparative study of 4 Mabs against sialyl-Tn-related antigens in normal, fetal and cancerous colonic mucosae. Tumor Biol 1990;11:111 (abstract).

6 Brandt JD, Wittpenn JR, Katz LJ, Steinmann WN, Spaeth GL. Conjunctival impression cytology in patients with glaucoma using long-term topical medication. $A m$ f Ophthalmol 1991;112:297-301.

17 Herreras JM, Pastor JC, Calonge M, Asensio VM. Ocular surface alteration after long-term treatment with an antiglaucomatous drug. Ophthalmology 1992;99:1082-8.

18 Broadway D, Grierson I, Hitchings R. Adverse effects of topical antiglaucomatous medications on the conjunctiva. Br f Ophthalmol 1993;77:590-6.

19 Steuhl K-P. Ultrastructure of the conjunctival epithelium. Dev Ophthalmol 1989;19:1-104.

20 Saini JS, Rajwanshi A, Dhar S. Clinicopathological correlation of hard contact lens related changes in tarsal conjunction of hard contact lens related changes in tarsal conjunc-
tiva by impression cytology. Acta Ophthalmol (Copenh) 1990;68:65-70. 